\title{
Einfach und bequem: Zahlen Sie Ihren Mitgliedsbeitrag per Lastschrifteinzug
}

Sie sind gewohnt, regelmäßig von uns die neusten Informationen aus der Radiologie zu erhalten. Nun möchten wir Ihnen ein wenig Zeit schenken - vorausgesetzt, Sie schenken uns Ihr Vertrauen. Indem Sie uns den Auftrag zum Lastschrifteinzug Ihrer Mitgliedsbeiträge geben, entfällt für Sie der aufwendige Überweisungsauftrag.

\section{Und so funktioniert's:}

Variante 1, von uns empfohlen: Loggen Sie sich im Mitgliederbereich der Deutschen
Röntgengesellschaft ein, der den neusten Datenschutz- und Sicherheitsstandards entspricht, und tragen Sie hier Ihre Bankverbindung ein: drg.de > Mitglieder $>$ Mitgliederbereich.

Variante 2: Füllen Sie das Formular zur Einzugsermächtigung aus. Dieses finden Sie auf www.drg.de > Mitglieder > Ihre Vorteile einer Mitgliedschaft > Einzugsermächtigung. Senden Sie das Formular ausgefüllt an uns zurück (per E-Mail an Frau Birgit Engelhardt, engelhardt@drg.de, per
Fax: 030-916 070-22 oder per Post an die Deutsche Röntgengesellschaft, ErnstReuter Platz 10, 10587 Berlin).

Den Rest erledigen wir für Sie. Ab Februar 2021 erfolgt dann die Zahlung Ihrer Mitgliedsbeiträge bequem und automatisch per Lastschrifteinzug. 